\title{
Next-Generation Sequencing in Blood Group Genomics: State of the Art and Perspectives
}

\author{
Christoph Gassner \\ Independent Researcher, Immunogenetics and Immunohematology, Zurich, Switzerland
}

Next-generation sequencing (NGS), or second-generation sequencing, is the catch-all term used to describe several high-throughput technologies for DNA sequencing $[1,2]$. The techniques are also known as massive (or massively) parallel or deep sequencing and allow for sequencing of DNA and RNA much more quickly, at a favorable price, and at scales at or beyond genome sizes in comparison to the previously used first-generation Sanger sequencing. Throughout the last decade, this development revolutionized the study of genomics and molecular biology $[3,4]$. Shortly after NGS, third-generation sequencing (TGS) technologies emerged with their distinguished feature of long single-molecule sequencing reads $[5,6]$. Read lengths of up to tens of thousands of base pairs on single molecules, even using native DNA as a direct analyte, again pushed genome assemblies to unprecedented quality.

The title "Next-Generation Sequencing in Blood Group Genomics: State of the Art and Perspectives" of this special issue of Transfusion Medicine and Hemotherapy accounts for the above-described new developments within the oldest aspect of Transfusion Medicine, namely blood groups.

Literally, all (research) is nothing without references. In analogy, interpretation of obtained sequencing results critically relies on comparison to established reference se- quences. Especially for blood group alleles described in the early days of molecular blood group typing, indeed single-nucleotide variations were identified; however, there is a pronounced lack of (comprehensive, full-length) reference sequences with proven serology available. To improve this situation, Fichou et al. [7] exemplarily report on their combined NGS/TGS-based analysis of ACKR 1 to create reference sequences for the blood group system Duffy.

Molecular typing of the human platelet antigen polymorphism is a prime example for routine-oriented techniques with relevance for Transfusion Medicine [8]. In this issue, Vorholt et al. [9] describe a novel method for the simultaneous genotyping of twelve different human platelet antigen systems by means of amplicon-based NGS. Using a comparable amplicon-based approach, Fürst et al. [10] report on their routine-oriented, highthroughput NGS method, again supporting the technique's capability of reliably delivering a multitude of blood group genotypes simultaneously analyzed among a large number of blood donors.

More than 20 years ago, Lo et al. [11] reported that noninvasive fetal $\mathrm{RhD}$ genotyping could be performed reliably with the use of fetal DNA from maternal plasma. However, proving negative results is limited by difficulties in distinguishing true negative results from false neg- 
ativity caused by insufficient amounts of cell-free fetal DNA [12]. From a technical point of view, proof of true negativity might be widely facilitated by targeted massively parallel sequencing of short DNA fragments from maternal cell-free fetal DNA and would allow for counting of fetal alleles for many single-nucleotide variations in parallel, as reviewed by Wienzek-Lischka et al. [13] in this issue. In rare cases, ABO blood group-caused hemolytic disease of the fetus and newborn can be especially severe in pregnant women with blood group $\mathrm{O}$, showing a high titer of anti-A or anti-B. Rieneck et al. [14] report on their NGS-based assay developed for $\mathrm{ABO}$ prediction of the fetus.

Besides the five invited reports, all focusing on NGS in blood group genomics, the readers of this issue will find a further original research submission by Eryilmaz et al. [15], overlapping with the two articles tackling prenatal testing by NGS but employing digital polymerase chain reaction as an alternative method for this purpose.

Another original research submission reports on two different $\sim 100$-kb deletions of GYPB causative of the GPB-deficient blood group MNS phenotype S-s-U- in Black Africans [16]. According to the first author of this article, "it was only the original analysis of NGS data coming from the 1000 human genome project (1000G), which allowed for a breakthrough in the exact description of the observed deletions, thereby ending a 15-year research odyssey on the molecular background of S-s-U-." "Indeed," he continued, "throughout the last decade, NGS revolutionized the study of genomics and molecular biology."

\section{References}

1 Ronaghi M, Karamohamed S, Pettersson B, Uhlén M, Nyrén P. Real-time DNA sequencing using detection of pyrophosphate release. Anal Biochem. 1996 Nov;242(1):84-9.

2 Behjati S, Tarpey PS. What is next generation sequencing? Arch Dis Child Educ Pract Ed. 2013 Dec;98(6):236-8.

3 Mardis ER. A decade's perspective on DNA sequencing technology. Nature. 2011 Feb; 470(7333):198-203.

4 Levy SE, Myers RM. Advancements in NextGeneration Sequencing. Annu Rev Genomics Hum Genet. 2016 Aug;17(1):95-115.

5 Thompson JF, Milos PM. The properties and applications of single-molecule DNA sequencing. Genome Biol. 2011;12(2):217.

6 van Dijk EL, Jaszczyszyn Y, Naquin D, Thermes C. The Third Revolution in Sequencing Technology. Trends Genet. 2018 Sep;34(9):666-81.

7 Fichou Y, Berlivet I, Richard G, Tournamille C, Castilho L, Férec C. Defining Blood Group Gene Reference Alleles by Long-Read Sequencing: Proof of Concept in the ACKR1 Gene Encoding the Duffy Antigens. Transfus Med Hemother. DOI: 10.1159/000504584.
8 Hayashi T, Hirayama F. Advances in alloimmune thrombocytopenia: perspectives on current concepts of human platelet antigens, antibody detection strategies, and genotyping. Blood Transfus. 2015 Jul;13(3):380-90.

9 Vorholt SM, Hamker N, Sparker H, Enczmann J, Zeiler T, Fischer J, et al. HighThroughput Screening of Blood Donors for Twelve Human Platelet Antigen Systems Using Next-Generation Sequencing Reveals Detection of Rare Polymorphisms and Two Novel Protein-Changing Variants. Transfus Med Hemother. DOI: 10.1159/000504894.

10 Fürst D, Tsamadou C, Neuchel C, Schrezenmeier $\mathrm{H}$, Mytilineos J, Weinstock C. Next-Generation Sequencing Technologies in Blood Group Typing. Transfus Med Hemother. DOI: $10.1159 / 000504765$.

11 Lo YM, Hjelm NM, Fidler C, Sargent IL, Murphy MF, Chamberlain PF, et al. Prenatal diagnosis of fetal RhD status by molecular analysis of maternal plasma. N Engl J Med. 1998 Dec; 339(24):1734-8.

12 Doescher A, Müller TH. Noninvasive prenatal blood group genotyping. Methods $\mathrm{Mol}$ Biol. 2015;1310:135-47.
13 Wienzek-Lischka S, Bachmann S, Fröhner V, Bein G. Potential of Next-Generation Sequencing in Noninvasive Fetal Molecular Blood Group Genotyping. Transfus Med Hemother. DOI: 10.1159/000505161.

14 Rieneck K, Egberg Hother C, Clausen FB, Jakobsen MA, Bergholt T, Hellmuth E, et al. Next Generation Sequencing-Based Fetal ABO Blood Group Prediction by Analysis of Cell-Free DNA from Maternal Plasma. Transfus Med Hemother. DOI: 10.1159/ 000505464.

15 Eryilmaz M, Müller D, Rink G, Klüter H, Bugert P. Introduction of Noninvasive Prenatal Testing for Blood Group and Platelet Antigens from Cell-Free Plasma DNA Using Digital PCR. Transfus Med Hemother. DOI: 10.1159/000504348.

16 Gassner C, Denomme G, Portmann C, Bensing KM, Mattle-Greminger M, Meyer S, et al. Two Prevalent $\sim 100$ kb GYPB Deletions Causative of the GPB Deficient Blood Group MNS Phenotype S-S-U- in Black Africans. Transfus Med Hemother. DOI: 10.1159/ 000504946 . 